\title{
MODEL ASSET PRICING YANG BERLAKU DI INDONESIA: STUDY KASUS SAHAM UNGGULAN
}

\author{
Yunan Surono \\ Dosen Fakultas Ekonomi Universitas Batanghari
}

\begin{abstract}
This study tested the influential factors in the estimation of stock return and compare the three models of asset pricing, i.e., Capital Asset Pricing Model, Three Factors Pricing models, and Four Factors Pricing Model. The purpose of this research is to obtain a model of asset pricing can provide estimated stock return with better among three types of models. The research sample is stocks LQ45 in Indonesia stock exchange (idx) during the period of 2005-2016. Regression analysis performed on variables, excess return market, size, book to market, and momentum is against the return of the monthly stocks fit each model to know the influence of variables and the feasibility of the model with the adjusted $R$ square. Different test ANOVA is performed to obtain the standard deviation of each model and difference significance between the three models. The results showed: (1) factors in excess of market return, size premium, value premium, and momentum factors effect on stock return, (2) based on independent variables constituting influence, CAPM, Three Factors Pricing models or Four Factors Pricing Model can capture the behavior of stock prices on issuers who are members of group LQ45 on Indonesia stock market, (3) based on the adjusted $R$ Square and standard deviation, Three Factors Pricing Model better than the CAPM and the Four Factors Pricing Model better than Three Factors Pricing Model, but all three models have a weak explanatory power as well as the results of significance of difference test that is not significant, so that the benefits of these models to estimated return expectations of stock market Indonesia is still questionable.
\end{abstract}

Keywords: market excess return, size, book to market, momentum, CAPM, Three Factors Pricing models, Four Factors Pricing Model.

\section{PENDAHULUAN}

Dalam dunia investasi, semua investor mengharapkan tingkat pengembalian (return) yang optimal. Namun tingkat pengembalian yang diterima oleh investor (actual return) tidak selalu sesuai dengan tingkat pengembalian yang diharapkan (expected return), dengan kata lain investor tidak mengetahui dengan pasti hasil yang akan diperoleh dari investasi. Keadaan ini menunjukkan bahwa investor menghadapi risiko investasi. Dalam membuat keputusan investasi, ada dua faktor yang paling penting dipertimbangkan, yaitu pengembalian yang diharapkan (expected return) dan risiko yang harus ditanggung (risk). Teori keuangan menyatakan bahwa apabila risiko suatu investasi meningkat, maka pemodal mensyaratkan tingkat keuntungan yang semakin besar, dengan demikian risiko merupakan faktor penting dalam keputusan investasi. Kemampuan untuk mengestimasi return suatu sekuritas merupakan hal yang sangat diperlukan oleh investor untuk banyak keputusan keuangan seperti prediksi biaya ekuitas keputusan investasi, manajemen portofolio, penganggaran modal, dan evaluasi kinerja. (Adisetiawan dan Surono, 2011)

Manajemen portofolio sangat penting bagi para investor, manajer investasi maupun peneliti yang terus mengembangkan asset pricing model untuk menemukan teknik terbaik dalam melakukan seleksi portofolio yang mampu memberikan pengembalian optimal. Studi mengenai asset pricing terus berkembang dan semakin menarik untuk diteliti, karena selalu menyisakan pro dan kontra berkaitan dengan model yang dapat menjelaskan perilaku variabel-variabel dalam investasi dengan lebih baik. CAPM (Capital Asset Pricing Model) menjadi model estimasi yang paling populer. Model asset pricing diteliti secara terpisah oleh Sharpe (1964), Lintner (1965), dan Black (1972) ini merupakan pengembangan dari seleksi portofolio model Markowitz (1952). Markowitz berasumsi bahwa preferensi investor hanya didasarkan pada return ekspektasi yang diinginkan dan besarnya risiko portofolio yang dapat ditoleransi oleh investor tanpa mempertimbangkan aktiva bebas risiko (risk free asset) sehingga model ini disebut juga dengan mean variance model. 
Risiko yang ada pada saham individu bisa dikurangi dengan menambah jumlah aset saham dengan membentuk sebuah portofolio. Semakin banyak jumlah saham yang ditambahkan dalam portofolio, maka risiko individu akan lebih kecil. Ukuran risiko yang digunakan dalam CAPM adalah beta. Beta adalah ukuran risiko sistematis suatu sekuritas yang tidak terhindarkan melalui diversifikasi. Beta merupakan pengukur volatilitas suatu sekuritas atau return portofolio terhadap return pasar (Jones, 2000:358). Volatilitas dapat didefinisikan sebagai fluktuasi dari return-return suatu sekuritas atau portofolio dalam periode waktu tertentu. Namun demikian, sebagai suatu model yang dianggap merupakan penemuan spektakuler, CAPM tidak terlepas dari berbagai kritik tajam, terutama karena asumsi-asumsi yang digunakan dalam CAPM kurang realistis. Selain itu, model CPAM juga menyisakan keraguan atas kemampuan beta dalam menjelaskan semua variasi dalam memperkirakan expected return dan menjelaskan hubungan ekuilibrium dalam pasar keuangan. Fama dan French (1992) meragukan model CAPM karena berbagai variabel kinerja saham yang sejak lama digunakan untuk memprediksi expected return seperti book-to-market (Stattman, 1980), size (Banz, 1981), earnings per Price (Basu, 1983), leverage (Bhandari, 1988).

Keraguan lain atas keakuratan CAPM adalah mengenai keakuratan beta sebagai variabel penjelas. Tandelilin (2003) mengemukakan bahwa terdapat kemungkinan error yang berasal dari (1) beta berubah sesuai lamanya periode observasi yang digunakan dalam analisis regresi; (2) indeks pasar yang digunakan sebagai proksi dari portofolio pasar belum merepresentasikan keseluruhan marketable asset dalam perekonomian; dan (3) perubahan variabel fundamental perusahaan seperti earning, arus kas, dan leverage akan merubah nilai dari beta. Melihat kondisi riil pasar, validitas CAPM seringkali dipertanyakan. Pada tahun 1992, Fama dan French membuat sebuah penelitian yang sangat berpengaruh hingga sekarang dengan mengkombinasikan variabel size, leverage, E/P, book-to-market, dan beta dalam sebuah penelitian single cross-sectional. Hasil penelitian tersebut mengungkapkan bahwa book-to-market equity dan size memiliki hubungan paling kuat dengan return. (Adisetiawan dan Surono, 2016)

Fama dan French (1993) memperluas model satu faktor menjadi model tiga faktor, dengan menambahkan rata-rata sensititivitas tingkat pengembalian saham ke ukuran perusahaan dan rasio book-tomarket. Return bulanan saham diregres terhadap market premium, size premium, dan book-to-market premium. Size premium merupakan selisih return portofolio saham berkapitalisasi pasar kecil dan saham berkapitalisasi pasar besar, yang dinotasikan sebagai SMB (small minus big). Fama dan French (1992) selaras dengan Banz (1981) menemukan hubungan negatif antara return dengan size, saham berkapitalisasi pasar kecil memiliki return lebih tinggi dibanding saham berkapitalisasi besar. Book-to-market premium merupakan selisih return portofolio saham dengan book-to-market tinggi dan portofolio saham dengan book-to-market rendah yang dinotasikan sebagai HML (high minus low). Sepakat dengan penelitian Stattman (1980) dalam Fama dan French (1992) diperoleh hubungan positif antara average return dan book-to-market, artinya bahwa saham dengan rasio book-to-market tinggi cenderung memiliki rata-rata pengembalian yang lebih tinggi dibanding perusahaan dengan rasio book to market rendah. Fama dan French (1993) memperluas CAPM menjadi three factors pricing model dengan menambahkan variabel size premium yang disebut SMB (Small Minus Big) dan value premium yang disebut HML (high minus low). Penelitian menunjukkan bahwa model penetapan harga tiga faktor atau three factor pricing model dapat menangkap anomali pasar lebih besar dibanding CAPM, kecuali anomali momen, seperti yang diungkap Fama dan French (1996), Tandelilin (2003).

Peare dan Bartholdy (2004) menemukan bahwa three factors pricing model tidak jauh lebih baik dibanding CAPM dengan angka R square hanya berkisar 5\%. Baik model tiga faktor maupun CAPM memiliki kekuatan penjelasan yang lemah, sehingga tidak satupun model yang cukup bermanfaat dalam estimasi return. Roger dan Securato dengan sampel penelitian di Brazil juga sepakat bahwa three factors pricing model lebih baik menjelaskan return dibanding CAPM, meskipun secara parsial book to market memiliki pengaruh yang tidak signifikan. Pandangan lain dikemukakan Porras (1998) bahwa anomali size dan book to market tidak berpengaruh terhadap variasi return.

Sebaliknya, CAPM masih terbukti memiliki peranan dalam estimasi return. Di samping beta pasar, tingkat pengembalian rata-rata saham berhubungan dengan ukuran perusahaan, rasio earning/price, dan rasio book-to-market equity, masih terdapat berbagai variabel yang telah diteliti berkaitan dengan expected return seperti pertumbuhan penjualan masa lalu, karakter pembalikan jangka panjang dan momentum jangka pendek 
(Jegadeesh dan Titman, 1993). Atas anomali ini, para akademisi telah menguji kinerja model alternatif yang dapat menjelaskan lebih baik mengenai tingkat pengembalian saham.

Carhart (1997) memperluas model three factors pricing model Fama dan French (1993) menjadi four factors pricing model dengan memperkenalkan faktor harga momentum sebagai faktor keempat. Faktor momentum merupakan faktor yang merepresentasikan kecenderungan perusahaan dengan past return negatif akan menghasilkan future return negatif, sedangkan perusahaan dengan past return positif akan menghasilkan future return positif. Berdasarkan karakteristik strategi ini, para pengamat sering menjuluki strategi investasi momentum dengan buy high sell higher (beli mahal, jual lebih mahal lagi). Strategi momentum dalam memprediksi return ekspektasi saham diukur dengan menghitung selisih antara value weighted return portofolio saham winners dengan value weighted return portofolio saham losers, yang dinotasikan sebagai WML (Winners Minus Losers). Jegadeesh dan Titman (2001) berpendapat bahwa terdapat bukti-bukti substansial yang menunjukkan bahwa kinerja saham yang baik atau buruk selama 3 sampai 12 bulan cenderung tidak mengalami perubahan berarti (tetap baik atau buruk) atas periode berikutnya. Hal ini juga didukung positif L'Her, J.F., Masmoudi, T. dan Suret, J.M. (2004) pada pasar saham di Kanada.

Bello (2008) membandingkan CAPM, three factors pricing model, dan four factors pricing model dan menemukan bahwa berdasarkan hasil uji kelayakan three factors pricing model lebih baik dalam memprediksi return dibandingkan CAPM dan four factors pricing model lebih baik dalam memprediksi return dibandingkan bahwa three factors pricing model. Namun demikian, perbedaan di antara ketiga model tersebut tidak signifikan. Di Indonesia sendiri, penggunaan faktor momentum dalam model asset pricing masih belum banyak dilakukan, karenanya penelitian ini juga berupaya untuk mengeksplorasi faktor momentum sebagai model asset pricing yang belum banyak diteliti pada pasar saham Indonesia.

\section{Landasan Teori \\ Asset Pricing Model \\ Capital Asset Pricing Model (CAPM)}

Bodie (2006) menyatakan bahwa Capital Asset Pricing Model (CAPM) merupakan hasil utama dari ekonomi keuangan modern. CAPM memberi prediksi yang tepat antara hubungan resiko suatu asset dan tingkat expected return, walaupun masih terjadi perdebatan dikalangan akademisi maupun para peneliti, CAPM masih digunakan secara luas dan masih mempunyai akurasi yang tepat untuk beberapa penelitian.

Sedangkan asumsi dari CAPM menurut Alexander, Sharpe and Bailey (1993), serta Lam (2005) adalah sebagai berikut: Investor mengevaluasi suatu portofolio dengan melihat expected return dan standar deviasi dari portofolio tersebut dari satu periode ke periode lainnya; Investor bersifat risk averse. Risk averse investor merupakan tipe investor yang lebih memilih investasi yang memiliki risiko paling kecil dan memiliki tingkat pengembalian yang tinggi; Individual asset tidak terbatas, maksudnya investor dapat membeli sebagian kecil dari saham yang diinginkan; Tidak ada pajak dan biaya transaski; Investor memiliki ekspektasi yang sama satu dengan yang lain; Informasi tersedia bebas bagi semua investor; Hanya ada satu 148ariab risiko yaitu systematic market risk yang tidak dapat dihilangkan; Tidak ada batasan untuk short sales; dan Investor dapat meminjam dan meminjamkan dalam jumlah yang tidak terbatas pada risk-free rate. Menurut Lam (2005) persamaan matematika CAPM adalah sebagai berikut:

$\mathrm{E}(\mathrm{Rp})=\mathrm{Rf}+\beta[(\mathrm{Rm})-\mathrm{Rf}]$

Dimana: $\mathrm{Rp}=$ Return Portofolio; $\mathrm{Rf}=$ Return risk free asset $; \mathrm{Rm}=$ Return market $;$ dan $\mathrm{B}=$ Beta (kepekaan saham i terhadap premium)

Persamaan tersebut mengatakan bahwa tingkat keuntungan yang diharapkan dari suatu portofolio (Rp) sama dengan tingkat risiko (Rf) ditambah premi risiko $[\beta(R m-R f)]$. Semakin besar risiko portofolio, semakin tinggi pula tingkat keuntungan yang diharapkan.

\section{Fama and French Three Factor Model}

Dalam Fama and French Three Factor Model ditambahkan dua faktor selain market risk yaitu faktor size dan faktor book to market dalam mengestimasi return saham. Faktor-faktor seperti size dan book to market tersebut termotivasi berdasarkan pengamatan Fama dan French terhadap historical average return pada saham perusahaan kecil dan pada saham dengan rasio book to market equity yang lebih tinggi bila dibandingkan 
dengan yang diprediksikan oleh Capital Asset Pricing Model. Penelitian tersebut yang akhirnya menimbulkan perkiraan bahwa size dan/atau book to market ratio mungkin merupakan faktor yang tidak terdeteksi oleh Capital Asset Pricing Model (Bodie, Kane, and Marcus, 2005). Fama dan French (2000) dalam penelitian lanjutannya menghasilkan $\mathrm{R}^{2}$ statistik untuk Fama and French Three Factor Model sebesar 0,91. Borchet et al (2003) dalam penelitiannya juga menemukan hasil yang hampir serupa yaitu Fama and French Three Factor Model memiliki $\mathrm{R}^{2}$ 0,92. Hal ini menunjukkan bahwa Fama and French Three Factor Model lebih baik dalam menjelaskan return. Beberapa penelitian lanjutan yang serupa juga dilakukan Connor (2001) dan Lam (2005) menunjukkan bahwa faktor selain market risk yaitu faktor book to market ratio dan faktor size secara signifikan berpengaruh positif. Dengan demikian, dapat dikatakan bahwa kekuatan faktor-faktor yang dipergunakan Fama and French Three Factor Model lebih baik bila dibandingkan dengan Capital Asset Pricing Model. Menurut Lam (2005) persamaan matematika Fama and French Three Factor Model sebagai berikut:

$\mathrm{E}(\mathrm{Ri})=\mathrm{Rf}+\beta[\mathrm{E}(\mathrm{Rm})-\mathrm{Rf})+(\mathrm{SMB})+(\mathrm{HML})$

Dimana: $\mathrm{E}(\mathrm{Ri})=$ Expected return $; \mathrm{Rf}=$ Return risk free asset $; \mathrm{E}(\mathrm{Rm})=$ Expected return market $; \beta=$ Beta; $\mathrm{SMB}=$ return portofolio yang dibuat berdasarkan size perusahaan kecil dikurangi size perusahaan besar; dan $\mathrm{HML}=$ return dari portofolio yang dibuat berdasarkan book to market equity yang tinggi dikurangi dengan book to market equity yang rendah.

Menurut Ang (1997), koeffisien beta dapat menunjukkan karakteristik suatu sekuritas. Jika $\beta i$ (saham individu) lebih besar dari 1 (satu), berarti kenaikan return sekuritas lebih tinggi dari kenaikan return pasar. Jika $\beta$ i lebih kecil dari 1 (satu) berarti kenaikan return sekuritas tersebut lebih rendah dari kenaikan return pasar. Secara matematis $\beta$ (Beta) dapat dihitung dengan rumus sebagai berikut:

$\beta=\frac{N \Sigma X Y-\Sigma X Y}{N \Sigma X^{2}-\Sigma X^{2}}$

Dimana $\mathrm{X}=$ Return Pasar (Rm); Y = Return Saham (Ri); N = Jumlah Data

Market capitalization biasanya digunakan untuk menuntun strategi investasi pada suatu negara. Setiap negara memiliki ukuran-ukuran size yang berbeda-beda. Borchet et al (2003) menyatakan bahwa faktor size atau yang disebut SMB - Small Minus Big didesain untuk mencoba mengestimasi tambahan return para investor yang memiliki historis berinvestasi pada perusahaan yang memiliki market capitalization yang kecil. Dalam prakteknya Beta size dihitung dengan cara rata-rata return enam portofolio yaitu $30 \%$ saham berkapitalisasi kecil dikurangi dengan rata-rata return dari 30\% saham yang berkapitalisasi besar pada satu periode.Menurut Fama and French (1992) persamaan SMB adalah sebagai berikut:

$\mathrm{SMB}=\{(\mathrm{S} / \mathrm{L}+\mathrm{S} / \mathrm{M}+\mathrm{S} / \mathrm{H})-(\mathrm{B} / \mathrm{L}+\mathrm{B} / \mathrm{M}+\mathrm{B} / \mathrm{H})\} / 3 \ldots \ldots .(4)$

Keterangan: $\mathrm{SMB}=$ return dari portofolio yang dibuat berdasarkan size perusahaan yang kecil dikurangi dengan size perusahaan yang besar; $\mathrm{S} / \mathrm{L}$ = portofolio perusahaan dengan market capitalization kecil (S) dan memiliki low book to market (L); S/M = portofolio perusahaan dengan market capitalization kecil (S) dan memiliki medium book to market $(\mathrm{M}) ; \mathrm{S} / \mathrm{H}=$ portofolio perusahaan dengan market capitalization kecil $(\mathrm{S})$ dan memiliki high book to market $(\mathrm{H}) ; \mathrm{B} / \mathrm{L}=$ portofolio perusahaan dengan market capitalization besar $(\mathrm{B})$ dan memiliki low book to market $(\mathrm{L}) ; \mathrm{B} / \mathrm{M}=$ portofolio perusahaan dengan market capitalization besar (B) dan memiliki medium book to market $(\mathrm{M})$; dan $\mathrm{B} / \mathrm{H}=$ portofolio perusahaan dengan market capitalization besar (B) dan memiliki high book to market $(\mathrm{H})$.

Book to market equity = book equity/market equity

Apabila book value memiliki nilai yang rendah yaitu kurang dari satu dengan market value, maka perusahaan tersebut memiliki book-to market equity yang rendah dan dikatakan bahwa saham perusahaan tersebut overvalued, dan sebaliknya apabila saham perusahaan tersebut mengalami undervalued, maka perusahaan dikatakan memiliki book to market equity yang tinggi. High Minus Low (HML) dihitung dengan cara rata-rata return dua portofolio yaitu 50\% saham yang memiliki rasio book to market tinggi dikurangi dengan rata-rata return 50\% saham yang memiliki rasio book to market rendah. Pesamaan High Minus Low adalah sebagai berikut:

$\mathrm{HML}=\{(\mathrm{S} / \mathrm{H}+\mathrm{B} / \mathrm{H})-(\mathrm{S} / \mathrm{L}+\mathrm{B} / \mathrm{L})\} / 2$

Dimana: $\mathrm{HML}=$ return dari portofolio yang dibuat berdasarkan book to market equity yang tinggi dikurangi dengan book to market equity yang rendah; $\mathrm{S} / \mathrm{L}=$ portofolio perusahaan dengan market capitalization kecil 
(S) dan memiliki low book to market equity $(\mathrm{L}) ; \mathrm{S} / \mathrm{H}=$ portofolio perusahaan dengan market capitalization kecil (S) dan memiliki high book to market equity $(\mathrm{H}) ; \mathrm{B} / \mathrm{L}=$ portofolio perusahaan dengan market capitalization besar (B) dan memiliki low book to market equity $(\mathrm{L})$; dan $\mathrm{B} / \mathrm{H}=$ portofolio perusahaan dengan market capitalization besar (B) dan memiliki high book to market equity $(\mathrm{H})$

HML yang positif mengindikasikan bahwa value stock lebih baik dibandingkan dengan growth stock dan jika HML negatif, maka growth stock lebih baik.

\section{Carhart Four Factor Model}

Beberapa pengembangan teori asset pricing yang telah disampaikan sebelumnya yakni teori Capital Asset Pricing (CAP), Arbitrage Pricing, Fama French Three Factor dan yang terbaru adalah Carhart's Four Factor Model. Beberapa peneliti mengatakan bahwa model Tiga faktor Fama dan French tidak dapat menangkap adanya anomali momentum. (Fama dan French, 1996). Selanjutnya, Jegadeesh dan Titman $(1993,2001)$ berpendapat bahwa terdapat bukti bukti yang substansial yang menunjukkan bahwa kinerja saham yang baik atau buruk selama tiga bulan hingga satu tahun cenderung tidak mengalami perubahan yang signifikan (tetap baik atau buruk) untuk periode berikutnya. Strategi trading moment yang mengeksploitasi fenomena ini secara konsisten telah memberikan keuntungan dipasar Amerika dan dipasar yang sedang berkembang.

Dengan situasi demikian, Carhart (1997), mengusulkan model four factor asset pricing dengan menambahkan moment pada model Fama dan French untuk menjelaskan tingkat pengembalian saham ratarata. Fama and French (1995) menunjukkan bahwa model tiga faktor dapat menjelaskan sebagian besar anomali termasuk pengaruh ukuran perusahaan dan rasio nilai buku terhadap nilai pasar (book to market), model tersebut tidak dapat menghitung pengaruh momentum. Carhart $(1995,1997)$ memperkenalkan model empat faktor yang memasukkan Fama French Three Factor Model ditambah faktor momentum. Carhart (1997), mengatakan bahwa Four Factor Model dapat menjelaskan variasi return portofolio berdasarkan return masa lalu dan konsisten dengan model pasar ekuilibrium dengan empat faktor risiko. Model Carhart mempertimbangkan faktor risiko Fama dan French yaitu risiko pasar (beta), firm size (SMB), book to market rasio (HML), dan menambahkan faktor momentum WML (Winner Minus Loser) atau biasa disebut juga UMD (Up Minus Down). Model Carhart empat faktor adalah sebagai berikut (Kampman, 2011):

$\mathrm{E}(\mathrm{R})=\mathrm{Rf}_{\mathrm{f}}+\beta\left(\mathrm{K}_{\mathrm{m}}-\mathrm{R}_{\mathrm{f}}\right)+\mathrm{b}_{\mathrm{smb}}(\mathrm{SMB})+\mathrm{bhml}(\mathrm{HML})+\mathrm{b}_{\mathrm{umd}}(\mathrm{UMD}) \ldots . .(6)$

Keterangan: R: Return i pada periode t; Rf : Risk-free rate pada periode t; Mk : Market premium, dimana Excess return on market dikurangi risk-free rate pada periode $\mathrm{t}(\mathrm{Rmt}-\mathrm{Rft})$; SMB: Return pada faktor "small minus big" (SMB) pada periode t; HML : Return pada faktor "high minus low" (HML) book-to-market pada periode t; WMLt : Return pada faktor "Winner Minus Loser" pada periode t; $\beta, \mathrm{y}, \delta, \theta$ : adalah faktor sensitivitas untuk variabel yang diperoleh dari regresi.

\section{Saham LQ45}

Indeks LQ45 adalah nilai kapitalisasi pasar dari 45 saham yang paling likuid dan memiliki nilai kapitalisasi yang besar dan merupakan indikator likuidasi. Indeks LQ45 menggunakan 45 saham yang terpilih berdasarkan likuiditas perdagangan saham dan disesuaikan setiap enam bulan (setiap awal bulan Februari dan Agustus). Saham-saham yang termasuk di dalam LQ45 terus dipantau dan setiap 6 bulan akan diadakan review (awal Februari dan Agustus). Apabila ada saham yang sudah tidak masuk kriteria maka akan diganti dengan saham lain yang memenuhi syarat. Tujuan indeks LQ45 adalah sebagai pelengkap IHSG dan khususnya untuk menyediakan sarana yang obyektif dan terpercaya bagi analisis keuangan, manajer investasi, investor dan pemerhati pasar modal lainnya dalam memonitor pergerakan harga dari saham-saham yang aktif diperdagangkan. 


\section{Definisi Operasional Variabel}

\section{Variabel Dependen}

Variabel dependen penelitian ini adalah return ekspektasi dari saham portofolio $E\left(R_{i}\right)$, yaitu tingkat pengembalian yang diharapkan investor atas saham $i$. Dalam model regresi penelitian asset pricing model (Sharpe, 1964 dan Fama, 1996), nilai variabel dependen diestimasi sebagai excess returns dari sekuritas tunggal, yaitu selisih antara return saham $i\left(R_{i}\right)$ dan tingkat suku bunga risiko atau risk free rate asset $\left(R_{f}\right)$. Return saham perusahaan $i$ pada bulan $t$ dihitung sebagai berikut:

$R_{i}=\frac{{\text { Harga Penutupan } \text { Saham }_{i, t}-\text { Harga Penutupan Saham }}_{i, t-1}}{\text { Harga Pentupan Saham }}$

Risk free rate of return $\left(R_{f, t}\right)$ adalah tingkat pengembalian yang diinginkan oleh investor dari sebuah investasi bebas risiko. Proksi investasi bebas risiko yang digunakan di Amerika Serikat adalah T-bill (Jones, 1996). Tbill adalah sekuritas pemerintah yang paling likuid, dimana investor akan memperoleh return dari pemerintah sebesar face value ditambah dengan bunga, sehingga dapat dikatakan bahwa return yang diterima investor tidak mengandung risiko. Di Indonesia risk free rate yang digunakan adalah suku bunga Sertifikat Bank Indonesia.

\section{Variabel Independen}

a. Rate of Return on Market $\left(R_{m}\right)$ merupakan tingkat pengembalian atas keseluruhan saham baik saham biasa maupun saham preferen yang ada di pasar secara tertimbang (value weighted) berdasarkan nilai kapitalisasi pasar. Di Indonesia digunakan Indeks Harga Saham Gabungan (IHSG). Return pasar $\left(R_{m}\right)$ bulan $t$ dihitung dengan rumus sebagai berikut:

$R_{m}=\frac{I H S G_{i, t}-I H S G_{i, t-1}}{I H S G_{i, t-1}}$

Sekali lagi karena di dalam pasar terdapat return bebas risiko, maka dalam model yang akan diuji, return pasar dalam regresi dihitung sebagai excess dari return pasar terhadap return bebas risiko yang dinotasikan sebagai $R_{m}-R_{f, t}$.

b. Size Premium (SMB), seperti pada penelitian Fama dan French (1996), Liew dan Vassalou (2000), serta L'Her (2004), firm size atau ukuran perusahaan dalam penelitian ini diukur berdasarkan kapitalisasi pasar atau market capitalization. Kapitalisasi pasar merupakan hasil perkalian antara jumlah agregat lembar saham terhadap harga penutupan pada pasar reguler. Berdasarkan kapitalisasi pasar diperoleh return portofolio SMB (Small Minus Big), yaitu selisih antara value weighted return portofolio saham kapitalisasi kecil dan value weighted return portofolio saham berkapitalisasi besar.

c. Book to Market Value Premium (HML), Book to Market Value merupakan rasio antara nilai buku terhadap nilai pasar dari saham. Book to Market dihitung dengan rumus sebagai berikut:

Book to Market $=\frac{\text { book value equity per share }}{\text { market value per share }}$

Berdasarkan rasio book to market diperoleh return portofolio HML (High Minus Low), yaitu selisih antara value weighted return portofolio saham yang memiliki book to market tinggi dan value weighted return portofolio saham yang memiliki book to market rendah.

d. Momentum (WML), momentum merupakan strategi investasi portofolio saham yang melakukan pembelian saham dengan performa baik pada masa lalu (winners) dan melakukan penjualan saham dengan performa buruk di masa lalu (losers). Pengaruh penggunaan strategi momentum dalam memprediksi return ekspektasi saham dapat diukur dengan menghitung selisih antara value weighted return portofolio saham winners dengan value weighted return portofolio saham losers, yang dinotasikan sebagai WML (Winners Minus Losers). Jegadesh dan Titman (1993) mendokumentasikan bahwa selama medium term horizon (tiga hingga dua belas bulan) perusahaan yang memiliki higher return di masa lalu cenderung menghasilkan abnormal return yang positif selama rentang waktu yang sama. Liew dan Vassalou (2000) menggunakan strategi momentum bulan $t-12$ untuk menguji pengaruh momentum dalam memprediksi return. Harsono (2008) menemukan bahwa pada ranking period $\mathrm{t}-12$ dan holding period 3 bulan menghasilkan abnormal return momentum investment strategy sebesar 1,039. Berdasarkan 
penelitian terdahulu, maka dalam penelitian ini strategi momentum diukur berdasarkan actual return 12 bulan yang lalu.

\section{Prosedur Pembentukan Portofolio.}

Prosedur pembentukan portofolio dalam penelitian ini menggunakan metode yang digunakan oleh Liew dan Vassalou (2000), yang disebut sebagai metode three sequential sort. Penelitian ini tidak menggunakan metode pembentukan portofolio dengan independent sort model Fama dan French (1996) karena jumlah saham yang menjadi sampel kecil, yaitu hanya 114 perusahaan. Penggunaan independent sort pada jumlah sampel yang kecil akan berakibat pada kurang akuratnya penggolongan saham-saham ke dalam kategori portofolio. Adapun prosedur pembentukan portofolio meliputi proses yang dijelaskan secara terperinci di bawah ini.

a. Mengurutkan saham-saham yang lolos sesuai kriteria sampel berdasarkan besarnya book to market value tiap bulan pada setiap tahun dalam periode penelitian mulai 2005 hingga 2016. Urutan saham berdasarkan book to market value mulai nilai terendah hingga tertinggi dibagi berdasarkan tritile, sehingga pada setiap bulan pada setiap tahun diperoleh tiga portofolio book to market sebagai berikut:

1) High, yaitu saham-saham yang termasuk dalam kategori $1 / 3$ saham dengan book to market tertinggi.

2) Medium, yaitu saham yang termasuk 1/3 saham dengan nilai book to market sedang, yaitu berada diantara kategori saham high dan low.

3) Low, yaitu saham-saham yang termasuk dalam kategori 1/3 saham dengan book to market terendah.

b. Setelah diperoleh tiga portofolio saham berdasarkan book to market, yaitu high, medium, dan low, kemudian dilakukan re-sort atau pengurutan ulang berdasarkan kapitalisasi pasar pada tiap porotofolio book to market tersebut. Dengan demikian, masing-masing kategori book to market dibagi kembali berdasarkan urutan kapitalisasi pasar ke dalam tiga sub kategori size sebagai berikut:

1) Small, yaitu saham-saham yang termasuk dalam kategori $1 / 3$ saham dengan kapitalisasi pasar terkecil.

2) Medium, yaitu saham yang termasuk $1 / 3$ saham dengan nilai kapitalisasi pasar sedang, yaitu berada diantara kategori saham small dan big.

3) Big, yaitu saham-saham yang termasuk dalam kategori 1/3 saham dengan kapitalisasi pasar terbesar. dengan demikian, setelah dilakukan sorting berdasarkan kapitalisasi pasar untuk tiap kategori book to market telah terbentuk 9 portofolio book to market - size setiap bulan pada tiap tahunnya.

c. Tiap portofolio book to market-size diurutkan kembali dengan strategi momentum berdasarkan urutan return pada bulan $t$-12. Return strategi momentum dihitung dengan rumus sebagai berikut:

Return $=\frac{\text { Harga Penutupan Saham }}{t-\text { Harga Penutupan Saham }_{t-12}}$

Dengan pengurutan ulang berdasarkan past year's return di atas, maka tiap portofolio book to market size dibagi lagi menjadi tiga kategori berdasarkan past year's return sebagai berikut:

1) Losers, yaitu saham-saham yang termasuk dalam kategori $1 / 3$ saham dengan past year's return terendah

2) Medium, yaitu saham yang termasuk 1/3 saham dengan past year's return sedang, yaitu berada diantara kategori saham winners dan losers.

3) Winners, yaitu saham-saham yang termasuk dalam kategori 1/3 saham dengan past year's return tertertinggi.

d. Setelah proses three sequential sort ini lengkap, maka telah terbentuk 27 portofolio (P1 sampai P27) berdasarkan book to market, size, dan momentum setiap bulan seperti tampak pada Tabel 3.1. Langkah selanjutnya adalah menghitung value weighted return untuk masing-masing portofolio dengan rumus sebagai berikut: value weighted return portofolio ${ }_{n}=$ $\sum_{i=1}^{n} \frac{\text { Kapitalisasi pasar saham }_{i}}{\text { Kapitalisasi pasar portofolio }}$ x actual return saham sa $_{i}$

Penghitungan return portofolio dengan value weighted penting artinya karena dapat mengurangi variasi serta dapat merepresentasikan perbedaan prilaku portofolio berkaitan dengan perbedaan size (Fama, 1993). Dengan demikian telah diperoleh 27 return per bulan pada setiap tahun. 
Portofolio yang telah terbentuk dipergunakan untuk menghitung nilai faktor SMB, HML, dan WML bulanan dengan prosedur sebagai berikut:

1. Penghitungan nilai faktor HML (High Minus Low), HML adalah perbedaan antara rata-rata tingkat pengembalian portfolio saham dengan rasio book to market yang dan rata-rata tingkat pengembalian portfolio saham dengan rasio book to market yang rendah. Berdasarkan portofolio yang telah dibentuk pada Tabel 3.1, HML dihitung dengan rumus sebagai berikut:

$\mathrm{HML}=1 / 9\{(\mathrm{P} 1-\mathrm{P} 19)+(\mathrm{P} 2-\mathrm{P} 20)+(\mathrm{P} 3-\mathrm{P} 21)+(\mathrm{P} 4-\mathrm{P} 22)+(\mathrm{P} 5-\mathrm{P} 23)+(\mathrm{P} 6-\mathrm{P} 24)+(\mathrm{P} 7-\mathrm{P} 25)+(\mathrm{P} 8-\mathrm{P} 26)+$ (P9-P27)\}

2. Penghitungan nilai faktor SMB (Small Minus Big), SMB adalah selisish nilai rata-rata tertimbang portofolio saham berkapitalisasi pasar kecil dan rata-rata tingkat pengembalian portfolio saham berkapitalisasi pasar besar. Berdasarkan portofolio yang telah dibentuk pada Tabel 3.1, SMB dihitung dengan rumus sebagai berikut:

$\mathrm{SMB}=1 / 9\{(\mathrm{P} 1-\mathrm{P} 7)+(\mathrm{P} 2-\mathrm{P} 8)+(\mathrm{P} 3-\mathrm{P} 9)+(\mathrm{P} 10-\mathrm{P} 16)+(\mathrm{P} 11-\mathrm{P} 17)+(\mathrm{P} 12-\mathrm{P} 18)+(\mathrm{P} 19-\mathrm{P} 25)+(\mathrm{P} 20-\mathrm{P} 26)$ $+(\mathrm{P} 21-\mathrm{P} 27)\} \quad(13)$

3. Penghitungan Nilai Faktor WML (Winner minus Looser), WML adalah perbedaan rata-rata pengembalian portofolio saham winner dikurangi pengembalian portofolio saham loser. Berdasarkan portofolio yang telah dibentuk pada Tabel 1, SMB dihitung dengan rumus sebagai berikut:

$\mathrm{WML}=1 / 9\{(\mathrm{P} 3-\mathrm{P} 1)+(\mathrm{P} 6-\mathrm{P} 4)+(\mathrm{P} 9-\mathrm{P} 7)+(\mathrm{P} 12-\mathrm{P} 10)+(\mathrm{P} 15-\mathrm{P} 13)+(\mathrm{P} 18-\mathrm{P} 16)+(\mathrm{P} 21-\mathrm{P} 19)+(\mathrm{P} 24-\mathrm{P} 22)$ $+(\mathrm{P} 27-\mathrm{P} 25)\}$

\section{HASIL}

Sampel yang telah dipilih, dibentuk portofolio bulanan dengan metode three sequential sort berdasarkan book to market, kapitalisasi pasar, dan return strategi momentum sehingga diperoleh 27 portofolio setiap bulan. Pembentukan portofolio dengan metode ini menyebabkan anggota dari setiap portofolio bisa berbeda-beda pada bulan satu dengan bulan berikutnya. Namun, hasil pengelompokan pada penelitian ini tampak bahwa ternyata persebaran saham dalam portofolio cenderung serupa. Artinya, portofolio pada bulan satu dengan bulan berikutnya cenderung memiliki anggota yang sama. Penghitungan return menggunakan metode value weighted seperti metode yang digunakan Fama (1996), Liew dan Vassalou (2000), dan L'Her (2004) sehingga dapat meminimalisir return variance. Lebih dari itu, penggunaan value weighted return dapat menggambarkan perilaku return berdasar besar-kecil saham dengan lebih baik (Fama, 1993).

\section{Pengujian Hipotesis 1}

Hipotesis 1: Dalam model CAPM, faktor excess return pasar berpengaruh terhadap return saham. Pengujian hipotesis pertama dilakukan dengan meregres variabel independen dalam model CAPM yaitu faktor excess return pasar terhadap variabel dependen yaitu return saham. Pengaruh variabel dependen terhadap variabel independen ditunjukkan Tabel 2 berikut ini.

\section{Tabel 1}

Hasil Uji t dan Uji F Model Regresi CAPM

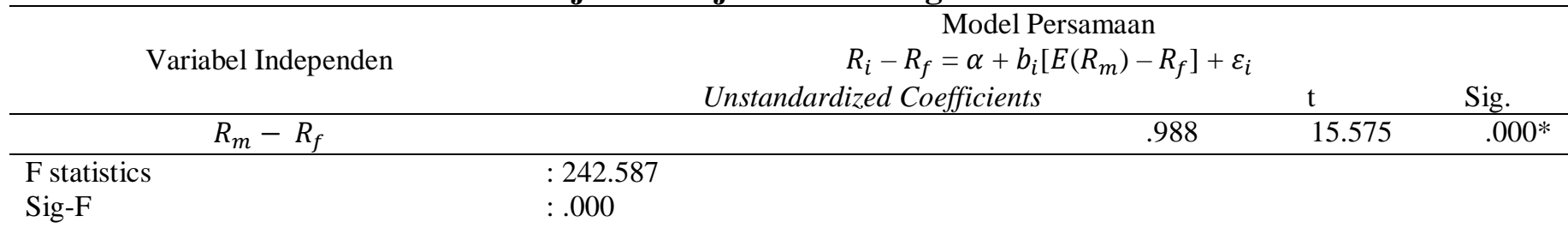

Sumber: Olahan data

Tabel 1 Tampak nilai probabilitas signifikansi return pasar sebesar 0.000 yang berada di bawah nilai 0.01 (tingkat signifikansi $\alpha 1 \%$ ) dengan koefisien regresi sebesar 0,988 . Hasil tersebut menunjukkan hipotesis 1 terdukung, bahwa terdapat pengaruh positif yang signifikan market premium sebagai satu-satunya variabel 
independen model CAPM terhadap return saham. Hal ini sesuai dengan teori bahwa risiko pasar (risiko sistematis) berpengaruh positif terhadap return.

\section{Pengujian Hipotesis 2}

Hipotesis 2: Dalam model Three Factors Pricing Model, faktor beta pasar, SMB, dan HML berpengaruh terhadap return saham.

Tabel 2

Hasil Uji T dan Uji F Model Regresi Three Factors Pricing Model

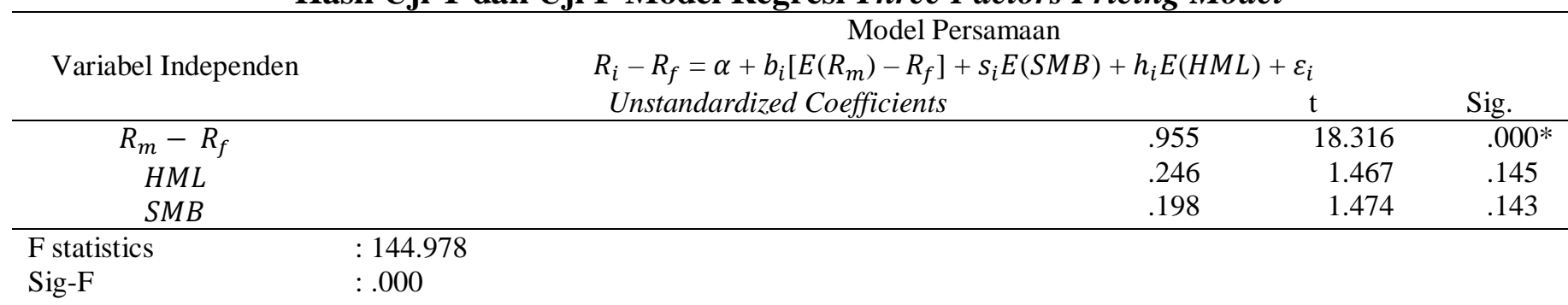

Sumber: Olahan data

Tabel 2 Menunjukkan nilai probabilitas signifikansi 154isbandi return pasar sebesar 0.000 yang berada di bawah nilai 0.01 (tingkat signifikansi $\alpha 1 \%$ ) dengan koefisien regresi sebesar 0,955. Faktor $H M L$ dan $S M B$ menunjukkan nilai probablitas signifikansi yang berada di atas nilai 0.10 (tingkat signifikansi $\alpha 10 \%$ ). Secara simultan, variabel-variabel independen berpengaruh secara signifikan dengan probabilitas signifikansi sebesar 0.000 yang bernilai di bawah 0,01; sehingga model regresi Three Factors Pricing Model dapat digunakan untuk memprediksikan harga saham. Dengan demikian, hipotesis 2 terdukung, bahwa dalam Three Factors Pricing Model, excess market premium, SMB, dan HML berpengaruh signifikan terhadap return saham.

\section{Pengujian Hipotesis 3}

Hipotesis 3: Dalam model Four Factors Pricing Model, faktor beta pasar, $S M B, H M L$, dan $W M L$ berpengaruh terhadap return saham.

Tabel 3 Menunjukkan nilai probabilitas signifikansi variabel return pasar dan WML sebesar 0.000 yang berada di bawah nilai 0.01 (tingkat signifikansi $\alpha 1 \%$ ) dengan koefisien regresi berturut-turut sebesar 0,977 dan 0,210. Faktor $H M L$ dan $S M B$ dan menunjukkan nilai probablitas signifikansi bernilai 0,175 dan 0,206 yang berada di atas nilai 0,10 (tingkat signifikansi $\alpha$ 10\%) dengan koefisien regresi sebesar 0,209 dan 0,156 . Secara simultan, variabel-variabel independen juga berpengaruh secara signifikan dengan probabilitas signifikansi sebesar 0.000 yang bernilai di bawah 0,01; sehingga model regresi Four Factors Pricing Model dapat digunakan untuk memprediksikan harga saham. Dengan demikian, hipotesis 3 terdukung, bahwa dalam Four Factors Pricing Model, excess market premium, SMB, HML, dan WML berpengaruh secara positif signifikan terhadap return saham.

\section{Tabel 3}

Hasil Uji t dan Uji F Model Regresi Four Factors Pricing Model

\begin{tabular}{cccc}
\hline & \multicolumn{2}{c}{ Model Persamaan } & \\
Variabel Independen & $R_{i}-R_{f}=\alpha+b_{i}\left[E\left(R_{m}\right)-R_{f}\right]+s_{i} E(S M B)+h_{i} E(H M L)+w_{i} E(W M L)+\varepsilon_{i}$ & $\mathrm{t}$ \\
Unstandardized Coefficients & .977 & 20.510 & $.000^{*}$ \\
$R_{m}-R_{f}$ & .209 & 1.364 & .175 \\
$H M L$ & .156 & 1.271 & .206 \\
$S M B$ & .210 & 5.454 & $.000^{*}$ \\
$W M L$ & $: 138.498$ & .210
\end{tabular}

Sig-F : $: 000$

Sumber: Olahan data 
Pengujian Hipotesis 4 dan Hipotesis 5

\section{Tabel 4}

Perbandingan $\boldsymbol{R}$-square dan Standar Deviasi Uji Beda Anova

\begin{tabular}{lcccr}
\hline & R square & & Adjusted $R$ square & \multicolumn{2}{c}{ Standar Deviasi } \\
\hline CAPM & .631 & .628 & 0.08103 \\
TFPM & .756 & .751 & 0.08773 \\
FFPM & .799 & .794 & 0.09013 \\
\hline
\end{tabular}

Sumber: Olahan data

Berdasarkan hasil goodness of fit uji regresi, diperoleh hasil bahwa Four Factors Pricing Model memiliki adjusted $R$ Square lebih tinggi jika dibandingkan dengan CAPM dan Three Factors Pricing Model. Standar deviasi dari uji beda dengan ANOVA Four Factors Pricing Model juga lebih besar jika dibandingkan dengan CAPM dan Three Factors Pricing Model. Dengan demikian Hipotesis 4 diterima, Four Factors Pricing Model lebih baik dalam menjelaskan return ekspektasi saham jika banding CAPM dan Three Factors Pricing Model.

Tabel 5

Hasil Uji Beda Residual dengan ANOVA

\begin{tabular}{lrrrr}
\hline & Sum of Squares & df & Mean Square & F \\
\hline Between Groups & 0.011113 & 3 & 0.003704 & 0.472341 \\
Within Groups & 4.486049 & 572 & 0.007843 & \\
Total & 4.497163 & 575 & & \\
\hline
\end{tabular}

Sumber: Olahan data

Hasil uji beda dengan ANOVA pada Tabel 5 Menunjukkan nilai $p$ value sebesar 0,7016 lebih besar dari alpha yang digunakan, yaitu 5\%. Dengan demikian, tidak terdapat perbedaan signifikan antara ketiga model.

Diterimanya hipotesis satu, dua, dan tiga, maka diperoleh dua implikasi penting. Pertama, penelitian ini menemukan bahwa selain dipengaruhi pasar, size, book to market, dan momentum memberikan kontribusi dalam pembentukan harga saham di Indonesia. Kedua, penelitian ini menemukan bahwa dilihat dari kontribusi variabel-variabel pembentuknya, Capital Asset Pricing Model, Three Factors Pricing Model, dan Four Factors Pricing Model dapat menjadi model estimasi harga dan return saham di Indonesia.

Pertanyaan selanjutnya yang harus dijawab adalah dari ketiga model tersebut, model manakah yang dapat memberikan estimasi return dengan lebih baik. Maka hipotesis selanjutnya bertujuan untuk menentukan model yang secara signifikan lebih baik dalam melakukan estimasi return. Metode yang digunakan dalam penelitian ini adalah semakin besar nilai adjusted $R$-Square dan semakin rendah nilai standar deviasinya, maka model tersebut lebih baik dibanding model lainnya (Pierre dan Bartholdy, 2004). Hasil uji Goodness of Fit menunjukkan adjusted $R$ Square CAPM sebesar 62,8\% dengan standar deviasi 0,08103. Sedangkan Three Factor Pricing Model memiliki adjusted $R$ Square sebesar 75,1\% dengan standar deviasi 0,08773. Three Factors Pricing Model menghasilkan adjusted $R$ Square lebih tinggi dan standar deviasi lebih tinggi jika dibandingkan dengan CAPM. Dengan demikian, hipotesis empat diterima, bahwa Three Factors Pricing Model lebih baik dalam mengestimasi expected return dibanding Capital Asset Pricing Model.

Untuk menguji hipotesis ke-lima hasil uji kelayakan dan standar deviasi Three Factors Pricing Model dan Four Factors Pricing Model. Hasil uji Goodness of Fit menunjukkan adjusted $R$ Square Three Factor Pricing Model memiliki adjusted R Square sebesar 75,1\% dengan standar deviasi 0,08773. Sedangkan Four Factor Pricing Model memiliki adjusted $R$ Square sebesar 79,4\% dengan standar deviasi 0,09013. Four Factors Pricing Model menghasilkan adjusted $R$ Square lebih tinggi dan standar deviasi lebih tinggi jika dibandingkan Three Factors Pricing Model. Dengan demikian, hipotesis lima diterima, bahwa Four Factors Pricing Model lebih baik dalam mengestimasi expected return dibandingkan Three Factors Pricing Model.

Meskipun nilai adjusted $R$ Square dan standar deviasi menunjukkan perbaikan dari model CAPM yang paling sederhana hingga model empat faktor, namun penelitian ini hanya memperoleh nilai adjusted $R$ Square yang kecil hanya berkisar $62,8 \% ; 75,1 \%$; dan 79,4\%. Artinya ketiga model ini meskipun semua variabel independennya berpengaruh secara signifikan, namun hanya mampu menjelaskan kurang dari 5\% variasi 
variabel dependennya, sedangkan sekitar 95\% dijelaskan oleh variabel-variabel yang tidak terwakilkan dalam penelitian ini.

Selain nilai adjusted $R$ Square yang rendah, perbedaan persentase adjusted $R$ Square antar model juga sangat tipis, hanya sekitar $1 \%$ saja. Secara sederhana telah tampak bahwa tidak ditemukan perbedaan yang signifikan antara ketiga model. Hal ini diperkuat dengan hasil uji beda residual antara ketiga model dengan ANOVA. Residual dari persamaan regresi merepresentasikan penyimpangan return aktual dengan return ekspektasi yang ditentukan model. Uji beda menghasilkan standar deviasi yang meskipun makin kecil untuk model CAPM hingga empat faktor, namun selisihnya tidak ada 1\%. Tabel ANOVA juga menunjukkan $\mathrm{F}$ hitung sebesar 0,000 lebih kecil dari F tabel, dan nilai signifikansi sebesar 1,000 (lebih besar dari $\alpha$.) Dapat disimpulkan bahwa perbedaan antara ketiga model tidak signifikan.

Hasil dari penelitian ini menemukan bahwa selain ditentukan oleh return dan risiko pasar, harga saham di Indonesia juga dipengaruhi oleh size premium dan value premium, serta faktor momentum. Berdasarkan kontribusi variabel independen penyusunnya, secara signifikan CAPM, Three Factors Pricing Model, maupun Four Factors Pricing Model dapat menjadi model dalam melakukan estimasi harga saham maupun estimasi return. Meskipun berdasarkan uji kelayakan model Three Factors Pricing Model memiliki adjusted $R$ Square lebih besar dibanding CAPM dan Four Factors Pricing Model memiliki adjusted R Square lebih besar dibandingkan Three Factors Pricing Model, namun ketiganya memiliki kekuatan penjelas yang lemah serta perbedaan yang tidak signifikan.

\section{DAFTAR PUSTAKA}

Adisetiawan, R., dan Surono, Yunan., 2011, Analisa Pengaruh Variabel-variabel Fundamental Terhadap Return Saham LQ45, Jurnal Ilmiah Univ. Batanghari Jambi, 11(2), 21-31

Adisetiawan, R., dan Surono, Yunan, 2016, Earning Management and Accounting Information Value: Impact and Relevance, Business, Management and Economics Research, 2(10), 170-179

A.Fauzi., Johar Arifin, dan M. Fakhrudin, (2001), Aplikasi Excel dalam Financial Terapan. Penerbit PT. Rlex Media Komputindo Kelompok Gramedia - Jakarta.

Alexander, Gordon J., William F. Sharpe, \& Jeffry V. Bailey. (1993). Fundamentals of Investment (2nd ed.). Englewood Cliff, New Jersey: Prentice Hall.

Almahmoud, Abdulaziz. I., (2014). Country Risk Ratings and Stock Market Movements: Evidence from Emerging Economy. International Journal of Economics and Finance; Vol. 6, No. 10.

Amman, Manuel \& Steiner, Michael,. (2008). Risk Factors For The Swiss Stock Market. Topics in Finance. Seminar at the University of St.Gallen. Switzerland

Ang, Robert. 1997. Buku Pintar Pasar Modal Indonesia. Jakarta: T.T.P.

An-Sing, C and Shih-Chuan, F. (2009). Uniform testing and portfolio strategies for single and multifactor asset pricing models in the Pacific Basin markets. Applied Economics, Vol. 41, No. 15, 1951-1964.

Arifin, Z. (2005). Teori Keuangan dan Pasar Modal, 1st ed.. Yogyakarta: Ekonisia.

Armstrong, F. (n.d.). Fama-French Three Factor Model. doi:http://investorsolution.com/blog/fama-french-three-factor- model/?s=Fama-

French\%20three\%20factor\%model

Asness, Cliff S., 1994, Variables That Explain Stock Returns, dissertation, University of Chicago

Baillie, Richard and Patrick McMahon, (1990), The Foreign Exchange Market: Theory and Econometric Evidence. Cambridge University Press, Cambidge.

Barvels, Dustin Wayne., (2014). "Using The Fama-French Five-Factor Model To Predict Industry Market Returns"., Thesis, PNRI, Retrieved 23 September 2016.

Basu, S (1983). The relationship between earnings yield, market value and reurns for NYSE common stocks. Journal of Financial Economics, (12), 129-156.

Bello, Z. (2008) A statistical comparison of the CAPM to the Fama-French three-factor model and the Carharts's model. Global Journal of Finance and Banking Issues Vol. 2. No. 2. 
Bodie, Z., Kane, A., \& Marcus, A.J. (2005). Investment (6th ed.). Boston: McGraw- Hill/Irwin. Connor, Gregory \& Sanjaya Sehgal. (2001). Test of The Fama and French Model in India. Discussion Paper 379. London: London School of Economics and Political Science. doi:http://eprint.Ise.ac.uk/25057/

Bouchet, Michel Henry (2003), "Country Risk Assesment; A Guide to Global Investment Strategy”. Wiley Finance. England.

Brealey, R.A., Myers, S.C, (1991), Principle of Corporate Finance, Fourth Edition, International Edition, McGraw-Hill, Inc.

Brigham, Eugene, F., Gapenski, Louis, C., and Davis Philip, R, (1999), Intermediate Finan-cial Management, Sixth Edition, The Dryden Press, Orlando.

Brigham, Eugene F., and Houston Joel F, (1998), Fundamentals of Financial Management, Eight Edition, The Dryden Press, Orlando

Brewer, T.L., and P. Rivoli, (1990), Politics and Perceived Country Creditworthiness in International Banking, Journal of Money, Credit and Banking, 22(3), pp. 357-369.

Burton and Inoue (1985), An appraisal of the early warning indicators of sovereign loan default in country risk evaluation systems, Management International Review, 25, 45-56

Carhart, Mark M. 1997. "On Persistence in Mutual Fund Performance.” Journal of Finance. 52:1, pp. 57-82.

Chen,N.F, Roll, R. And Ross, S., A. (1986) "Economic Forces and the Stock Market", The Journal of Business, Vol. 59, No.3, P. 383-403.

Damar Hardianto dan Suherman, 2007. "Pengujian Fama-French Three- Factor Model di Indonesia". Jurnal Keuangan dan Perbankan, Vol. 13, No. 2 Mei, Hal. 198-208.

Darmadji Tjipto dan Hendry M Fakhruddin, (2001). Pasar Modal di Indonesia, Salemba Empat, Jakarta.

Davis,J.L., Fama,E.F., French,K.R.,(2000). Characteristics, Covariances, and Average Returns: 1929 to 1997. Journal of Finance, Vol.55, Issue 1, P.389-406.

Dayala, R. (2012). The Capital Asset Pricing Model: A Fundamental Critique. Business Valuation Review: Spring 2012, 31(1), 23-34. doi:http://dx.doi.org/10.5791/BVR-D-12-00001.1

Dede Wirawan dan Umi Murtini, (2008). Perbandingan Fama dan French Three Factor Model dengan CAPM. Jurnal Riset Akuntansi dan Keuangan, 4(2), h: 132-145.

Didit Herlianto, (2013), Manajemen Investasi Plus Jurus Mendeteksi Investasi Bodong, Penerbit Gosyen Publishing, Yogyakarta.

Dimson, Elroy (1979), "Risk measurement when shares are subject to infrequent trading" Journal of Financial Economic, Vol 7, Issue 2, June 1979, p.197-226.

Drew, Michael E., Tony Naughton, and Madhu Veeraraghavan, (2002), Firm Size, Book-to-Market Equity and Security Returns: Evidence from the Shanghai Stock Exchange, Symposium on Stock Markets: Risk, Return and Pricing, Queensland University of Technology/Economics Society of Australia, Brisbane, 16 December.

Elton, E.J., Gruber, M.J., \& Das, S.H. (1993). Efficiency With Costly Information: A Reinterprtation of Evidence from Managed Portfolios. Review of Financial Studies, 6(1), 1-22.aff, R. (2001). An Examination of The Fama and French Three Factor Model UsingCommercially Available Factors. Australan Journal of Management, 26(1),1-17.

Fama, E.F., \& French, K.R. (1992). The Cross Section of Expected Return. The Journal of Finance, 47(2), 427-464.

Fama, E.F., \& French, K.R. (1993). Common Risk Factors in the Return on Stocks and Bonds. Journal of Financial Economics, 33(1), 3-56.

Fama, E.F., \& French, K.R. (1995). Size and Book to Market Factoe in Earning and Return. The Journal of Finance, 50(1), 131-155.

Fama, E.F., \& French, K.R. (2004). The Capital Asset Pricing Model: Theory and Evidence. Journal of Economics Peerpective, 18(3), 25-46.

Fama, E.F., \& French, K.R. (2006). The Value Premium and The CAPM. The Journal of Finance, 61(5), 21632185. 
Gallagher, Timothy J., \& Joseph, D. Andrew. (2003). Financial Management Principles and Practice (3rd ed.). New Jersey: Prentice Hall.

Guidi, M. \& Davies, D. (2000): The Structural Characteristic Evidence on Risk Factors: Characteristics, Risk Factors and Risk Premia., Social Science Research Network,

Glabadanidis, Paskalis (2014), Absence of Arbitrage Valuation_A Unified Framework for Pricing Assets and Securities, Palgrave Macmillan

Gujarati, Damodar, N, (2003), Basic Econometrics, "Fourth Edition,International Edition, Mcgraw-Hill

Harianto dan Sudomo, (2001), Merger dan Akuisisi, Jurnal Manajemen.

Hartono, Jogiyanto.(2013), Teori Portofolio Dan Analisis Investasi, ED VII, Cet.III, Yogyakarta, BPFEYogyakarta.

Husnan, Suad.(2009), Dasar-Dasar Teori Portofolio dan Analisis Sekuritas, Ed IV, Cet.II, Yogyakarta: UPP STIM YKPN.

Howell (ICRG), 2017. The handbook of country and political risk analysis.

Imam Ghozali, 2007. "Aplikasi Analisis Multivariate dengan Program SPSS”. Edisi 3, Universitas Diponegoro, Semarang

Indraseno, Jimmy, Dimas Wahyu (2007) Pengujian model penilaian aset: CAPM vs Fama-Perancis tiga faktor model pada saham LQ 45 di Bursa Efek Jakarta (periode 2004-2006). Master tesis, Widya Mandala Surabaya Universitas Katolik.

Indriantoro, Nur., \& Supomo, Bambang. (2002). Metode Penelitian Bisnis untuk Akuntansi dan Manajemen (1st ed.). Yogyakarta: BPFE.

Jegadesh \& Titman. (1993), "Returns to Buying Winners and Selling Losers: Implications for Stock Market efficiency" Journal of Finance, 48: 65-91.

Juttner, D. Johannes (1992). International finance and global investments. Melbourne : Longman Cheshire

Kent L. Womack; Ying Zhang. (n.d.). Understanding Risk and Return, the CAPM, and the Fama-French Three-Factor Model. Tuck Case No. 03-111. doi:http://ssrn.com/abstract=481881

Lambert, M \& Hübner, G. (2014). Size Matters, Book-To-Market Does Not! The Fama-French Empirical CAPM Revisited. Presented at 12th annual Paris Finance Meeting. Paris 18 December, 2014.

Lam, K. (2005). Is The Fama \& French Model Better Than CAPM? Master Thesis in Economics. Somone Fraser University.

Lintner, J, (1965). "Security Prices, Risk and Maximal Gains from Diversivication". Journal of Finance 20,: 587-615.

, 1965. "The Valuation of Risk Assets and the Selection of Risky Investments in Stock Portfolios and Capital Budgets". Review of Economics and Statistics, Vol. 47, pp. 13-37.

Madyan, Muhammad Dan Gancar Candra Premananto, (2004) "Perbandingan Keakuratan CAPM dan APT dalam Memprediksi Tingkat Pendapatan Industri Perbankan Dan Lembaga Keuangan Selain Bank Baik Sebelum Dan Semasa Krisis Ekonomi Di Bursa Efek Jakarta.” Laporan Penelitian Hal 11-15,.

Mankiw, N Gregory, (2009), Macroeconomics, Worth PublishersMankiw, N, Gregory, 2003, Macroeconomics $5^{\text {th }}$ Edition. First Published in the US by Worth Publishers, New York and Basingstone. Edisi Indonesia, Penerbit Erlangga, Jakarta.

Miller, Merton H. and Myron Scholes. 1972. "Rates of Return in Relation to Risk: A Reexamination of Some Recent Findings," in ed. Michael C. Jensen, Studies in the Theory of Capital Markets. New York: Praeger.

Mossin, Jan. 1966. "Equilibrium in a Capital Asset Market." Econometrica, V. 34, No. 2: pp 768-83.

Mudrajad, (1996) Metode Riset Untuk Bisnis \& Ekonomi. Erlangga saat. Jakarta.

Parkin, Michael. (2011), Macroeconomics, 10th Edition (Pearson Series in Economics), Prentice Hall.

Pasaribu, R.B.F. (2009). Model Fama dan French Sebagai Pembentukan Portofolio Saham di Indonesia. Jurnal Akuntansi \& Bisnis. Vol. 9 (1) : 1-12.

Rahul, Verma \& Priti Verma, (2014). Country Risk and Macroeconomic Factors: Evidence from Asian Markets. Journal of Applied Business and Economics vol. 16(5). 
Rehnby, Nicklas (2016), Does the Fama-French three-factor model and Carhart four-factor model explain portfolio returns better than CAPM? - A study performed on the Swedish stock market.

Reilly, Frank, K., and Brown, Keith, (2003). "Investment Analysis and Portfolio Management". Seventh Edition, USA: South-Western

Roll, R. And Ross, S., A.(1984) "Critical Reexemanation of the Empirical Evidence on the Arbitrage Pricing Theory, Reply", Journal of Fianace, Vol. XXXV.

Ross, S, (1976). "The Arbitrage Pricing Theory of Capital Asset Pricing". Jornal of EconomicTheory 13: 341-360.

Ross, Stephen A., Randolph W.westerfield, dan Jeffrey Jaffe. (2010). Corporate Finance, Ninth Edition, Boston: McGraw-Hill.

Sharpe, W. F, (1964), Capital Asset Prices: A Theory of Market Equilibrium under Conditions of Risk, Journal of Finance vol. 19, no. 3, pp. 425-442.

Sharpe, W.F, (1963). "A Simplified Model For Protfolio Analysis". Management Science, January.

Slavin, Stephen (2008), Macroeconomics, McGraw-Hill_Irwin

Stephen Ross, Randolph Westerfield, \& Bradford Jordan. (2015). Fundamentals of Corporate Finance (11th ed.). New York: McGraw- Hill.

Sugiyono. (2010). Statistika untuk Penelitian. Bandung: Alfabeta.

Tandelilin, Eduardus. (2001). Portofolio dan Investasi Teori dan Aplikasi, Edisi pertama, Yogyakarta: Penerbit Kanisius

Penerbit Kanisius

Tsangarakis, N. V. (1996). Shareholder Wealth Effect of Equity Issue in Emerging Markets: Evidence from Rights Offerings in Greece. Financial Management, 25(3), 21-32.

Van Horne, J.C \& Wachowicz, J.M, Jr, (2001), Fundamental of Financial Management, Eleventh Edition, Prentice-Hall, Inc, Upper Saddle River, New Jersey.

Yuningsih, I. dan Yudaruddin, R. 2007. Pengaruh Model Tiga Faktor terhadap Return Saham. Jurnal Akuntabilitas 7:79-84.

Zhang, Qianwen.(2007). What Kind Of Asset Pricing Model Works In Emerging Markets? A Case Study For The Chinese Stock Markets. Thesis, PNRI, Retrieved; 23 September 2016. 